\title{
PELATIHAN PEMBUATAN SOAL BERBASIS DIGITAL BAGI GURU SMA DI ERA REVOLUSI INDUSTRI 4.0
}

\author{
Trie Utari Dewi ${ }^{1}$, Sri Lestari Handayani ${ }^{2}$ \\ 1 Universitas Muhammadiyah Prof. Dr. Hamka. \\ korespondensi email: trie.utari.dewi@uhamka.ac.id \\ Universitas Muhammadiyah Prof. Dr. Hamka. \\ email: srilestarih@uhamka.ac.id
}

\begin{abstract}
The challenges of the times in the era of the Industrial Revolution 4.0 or IR 4.0 need to be faced and responded by the actors in the world of education, teachers are no exception. Teachers are required to constantly innovate in learning including the evaluation process. Evaluation tools used can be technology based. The purpose of this community service activity is to conduct training on making digital-based questions using the application kahoot. This community service activity partnered with SMA PGRI 3 Jakarta. There were 22 participants in the community service activities, namely teachers at SMA PGRI 3. The method of this community service activity was distance training using the zoom meeting application. There are two sessions in this training, namely the first session in the form of understanding and strengthening related to digital literacy in the world of education and the second session in the form of a demonstration on how to make evaluation questions using the Kahoot application. After the community service, teachers and teachers at SMA PGRI 3 were able to create questions based on the Kahoot application. The final stage of this service activity was evaluated. Based on the results of the evaluation conducted by the implementation team and the school it can be stated that the training carried out was successful and went smoothly.
\end{abstract}

Keywords: question making; digital; kahoot.

\begin{abstract}
ABSTRAK
Tantangan perkembangan zaman di era Revolusi Industri 4.0 atau IR 4.0 perlu dihadapi dan direspon oleh para pelaku dunia pendidikan, tidak terkecuali oleh para guru. Guru dituntut untuk senantiasa berinovasi dalam pembelajaran termasuk proses evaluasi. Alat evaluasi yang digunakan dapat berbasis teknologi. Tujuan kegiatan pengabdian masyarakat ini adalah menyelenggarakan pelatihan pembuatan soal berbasis digital menggunakan aplikasi kahoot. Kegiatan pengabdian masyarakat ini bermitra dengan SMA PGRI 3 Jakarta. Peserta kegiatan pengabdian masyarakat ini berjumlah 22 orang yaitu bapak dan ibu guru di SMA PGRI 3. Metode kegiatan pengabdian ini adalah pelatihan jarak jauh menggunakan aplikasi zoom meeting. Terdapat dua sesi pada pelatihan ini yaitu sesi pertama berupa pemahaman dan penguatan terkait literasi digital di dunia pendidikan dan sesi kedua berupa demonstrasi cara membuat soal evaluasi dengan menggunakan aplikasi Kahoot. Setelah dilakukan kegiatan pengabdian, bapak dan ibu guru di SMA PGRI 3 sudah dapat membuat soal berbasis aplikasi Kahoot. Tahap akhir kegiatan pengabdian ini
\end{abstract}


dilakukan evaluasi. Berdasarkan dari hasil evaluasi yang dilakukan tim pelaksana dan pihak sekolah dapat dinyatakan bahwa pelatihan yang dilakukan berhasil dan berjalan dengan lancar.

Kata Kunci: pembuatan soal; digital; kahoot.

\section{PENDAHULUAN}

Saat ini manusia dihadapkan dengan tantangan zaman yang semakin berkembang khususnya di era Revolusi Industri 4.0 atau biasa disingkat IR 4.0. Tantangan ini juga merupakan suatu hal yang perlu dihadapi dan direspon oleh para pelaku dunia pendidikan, tidak terkecuali oleh para guru. Guru sebagai agen pembelajaran tidak hanya membuat rencana dan melakukan proses pembelajaran, tetapi juga mengevaluasi dengan melakukan penilaian terhadap seluruh proses pembelajaran. Hal ini sebagaimana permendiknas nomor 16 tahun 2007, bahwa kompetensi inti seorang guru diantaranya adalah melakukan penilaian dan mengevaluasi hasil belajar (Purnanto \& Mahardika, 2016). Salah satu cara untuk melakukan evaluasi tersebut yaitu melalui hasil tes belajar.

Dalam menghadapi tantangan IR 4.0, para guru harus dapat berinovasi dan memiliki keterampilan dalam membuat soal berbasis digital. Hal ini dikarenakan sekolah yang telah memanfaatkan teknologi digital dalam proses pembelajaran berarti sekolah tersebut telah mampu menjawab tantangan perkembangan zaman di era revolusi 4.0. Dengan begitu, proses pembelajaran tidak hanya terbatas oleh ruang dan waktu, namun sebaliknya, proses pembelajaran dapat terus berlangsung tanpa adanya batas ruang dan waktu.

Hal ini juga berlaku bagi guru-guru di SMA PGRI 3 yang berjumlah sebanyak 24 orang, sebagai pendidik dituntut untuk dapat beradaptasi dengan perkembangan zaman. Namun sayangnya, berdasarkan hasil wawancara serta survei secara langsung di SMA PGRI 3, para guru di sekolah belum mengikuti perkembangan teknologi yang ada, masih banyak guru yang tidak paham cara membuat soal berbasis digital dan kurangnya wawasan dan inovasi guru terhadap media digital. Selain itu, sistem ujian di SMA PGRI 3 masih bersifat konvensional, yaitu menggunakan kertas soal dan lembar jawaban. Hal ini dapat terlihat ketika proses evaluasi belajar berlangsung seperti kegiatan Ujian Tengah Semester (UTS) dan Penilaian Akhir Sekolah (PAS). Kegiatan UTS dan PAS di SMA PGRI 3 masih dilakukan secara konvensional.

Pendidikan pada era Revolusi Industri 4.0 seharusnya setiap sekolah yang sudah menerapkan kurikulum 2013 juga dapat menjawab tatangan tersebut dengan mengikuti perkembangan teknologi, yaitu melalui pembuatan soal berbasis digital. Dengan adanya model pembelajaran digital, para guru dipermudah dalam membuat bahan atau buku ajar yang sebagai salah satu bagian tanggungjawabnya mengikuti berkembangnya ilmu pengetahuan dan teknologi, serta mengembangkan diri dalam meningkatkan wawasan dan mengontrol kegiatan belajar peserta didik (Darmaningrat et al., 2018). 
Kondisi tersebut melatarbelakangi perlu diadakannya pelatihan pembuatan soal berbasis digital bagi guru-guru di SMA PGRI 3, hal ini bertujuan untuk mengembangkan kemampuan guru dalam membuat soal berbasis digital serta meningkatkan wawasan digital dan kompetensi TIK (Teknologi Informasi dan Teknologi) para guru.

Adapun pelatihan pembuatan soal berbasis digital yang dilakukan yaitu menggunakaan aplikasi Kahoot. Kahoot merupakan salah satu teknologi evaluasi pembelajaran yang dilakukan melalui permainan secara individu maupun berkelompok (Putri \& Asrori, 2019). Dipilihnya penggunaan aplikasi Kahoot untuk pelatihan pembuatan soal berbasis digital karena platform tersebut menggabungkan antara evaluasi pembelajaran dengan permainan interaktif, sehingga lebih menarik minat peserta dalam mengikuti evaluasi pembelajaran (Correia dan Raquel dalam Putri \& Asrori, 2019). Selain itu, aplikasi Kahoot tidak hanya dapat digunakan pada evaluasi pembelajaran di kelas secara langsung, tetapi juga dapat dilakukan evaluasi pembelajaran dengan jarak jauh seperti kondisi yang terjadi saat ini di tengah wabah Covid19. Dengan begitu, para siswa dapat belajar dan berlatih menjawab soal-soal secara mandiri di manapun dan kapanpun. Hal ini sebagaimana yang diungkapkan oleh (Putri \& Muzakki, 2019) bahwa alat komunikasi yang semakin canggih dapat memudahkan siswa dan pengajar dalam memperoleh informasi yang dibutuhkan setiap saat sehingga lebih memudahkan dalam mencari bahan dan metode evaluasi dengan memanfaatkan beragam teknologi yang ada.

\section{METODE PELAKSANAAN}

Kegiatan pengabdian masyarakat berupa Pelatihan Pembuatan Soal Berbasis Digital Pada Guru-Guru di Sekolah. Penerapan pelatihan ini berbasis digital dimana pelatihan ini dilakukan melalui pertemuan dengan menggunakan aplikasi Zoom. Hal ini dikarenakan kondisi Negara yang sedang terserang wabah Covid-19, sehingga segala kegiatan harus dengan jarak jauh. Peserta kegiatan terdiri dari 22 orang guru SMA PGRI 3.

Metode yang diterapkan dalam kegiatan ini yaitu metode ceramah dan demonstrasi serta simulasi. Metode ceramah dan diskusi terbuka, dipilih untuk memberikan pemahaman dan penjelasan tentang literasi digital dan tantangan guru dalam menghadapi era revolusi 4.0. sedangkan metode demonstrasi dipilih untuk menunjukkan kepada guru tentang cara membuat soal dengan menggunakan aplikasi Kahoot. Adapun metode simulasi digunakan agar peserta kegiatan dapat mempraktekkan secara langsung sesuai dengan materi yang telah diberikan. Cara ini dapat memperlihatkan sejauh mana kemampuan peserta dalam membuat soal berbasis digital khususnya dalam menggunakan aplikasi Kahoot.

Kegiatan dibagi menjadi dua sesi yaitu sesi I terkait literasi digital dan sesi I berupa demontrasi dan simulasi pembuatan soal berbasis aplikasi Kahoot. Selanjutnya guru diminta untuk menyelesaikan secara mandiri 
pembuatan soal tersebut dan dikumpulkan hasilnya kepada kepala sekolah. Instrument yang digunakan berupa aplikasi Kahoot, kuesioner evaluasi berbentuk google form, dan dokumentasi serta video kegiatan. Penggambaran metode dan alur kegiatan dapat dilihat pada gambar 1.

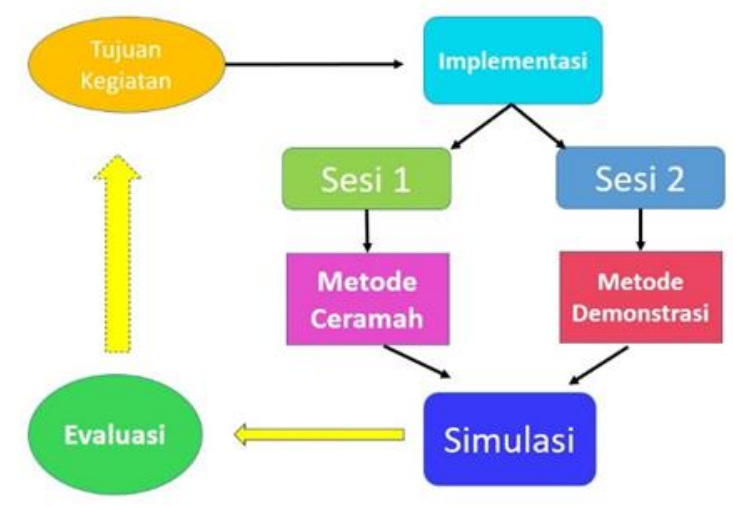

Gambar 1. Diagram metode dan alur kegiatan

\section{HASIL DAN PEMBAHASAN}

Kegiatan mengabdian diri di dalam masyarakat merupakan bagian dari tridarma perguruan tinggi secara umum dan caturdarma perguruan tinggi Muhammadiyah secara khusus. Pengabdian masyarakat yang telah dilaksanakan berupa "Pelatihan Pembuatan Soal Berbasis Digital Bagi GuruGuru Sekolah di Era Revolusi Industri 4.0". Mitra kegiatan pengabdian masyarakat ini adalah SMA PGRI 3 Jakarta. Kegiatan pengabdian pada masyarakat ini dilakukan pada Jumat, 17 April 2020. Pelaksanaan kegiatan ini berbeda dengan kegiatan pengabdian sebelum-sebelumnya. Pelatihan dilakukan dengan menggunakan aplikasi Zoom Meeting. Zoom Meeting merupakan salah satu aplikasi yang dapat meeting jarak jauh. Pelaksanaan zoom meeting menjadi pilihan tim pelaksana pengabdian dan mitra kegiatan yaitu SMA PGRI 3 dikarenakan beberapa pertimbangan yaitu (1) kondisi wabah covid-19 yang sedang terjadi di Jakarta, (2) pelaksanaan bekerja dari rumah bagi guru dan tim pelaksana, (3) pelaksanaan Pembatasan Sosial Berskala Besar (PSBB) di Jakarta di mana salah satunya adalah mengurangi kerumunan atau pertemuan lebih dari 5 orang, dan (4) pihak SMA PGRI 3 Jakarta tetap menginginkan adanya pelatihan ini secara tatap muka meskipun dengan jarak jauh. Oleh karena itu, pelatihan ini mempertemukan tim pelaksana dengan peserta melalui Zoom Meeting. Hal ini menjadi secara tidak langsung telah mempekuat pelatihan ini yang berkaitan dengan digital literasi dimana guru diajarkan untuk menggunakan literasi digital yang dimiliki.

Pelatihan ini dimulai pukul 13.00 WIB. Sebelum dimulai, tim pelaksana menunggu kehadiran semua guru untuk masuk ke grup di Zoom Meeting. Kegiatan ini melibatkan salah satu mahasiswa yang bertugas menjadi 
pembawa acara di kegiatan pelatihan ini. Sebelum pelatihan dimulai, mitra kegiatan ini yaitu SMA PGRI 3 Jakarta dipersilakan untuk memberikan sambutan. Sambutan dilakukan oleh Kepala SMA PGRI 3. Agenda selanjutnya berupa paparan materi dari tim pelaksana pengabdian masyarakat ini. Paparan materi terbagi menjadi dua sesi yaitu sesi 1 berupa ceramah dan diskusi tentang literasi digital dan tantangan guru di era revolusi industri 4.0. Literasi digital dapat dinyatakan sebagai kemampuan seseorang untuk menentukan arah jalan dalam lingkup digital dan informasi dalam rangka menemukan, mengevaluasi hingga menolak atau menerima informasi tersebut (Belshaw, 2011). Seseorang yang memiliki literasi digital yang baik akan mampu menjawab tantangan jaman, termasuk guru. Guru dapat menggunakan hingga memanfaatkan konten-konten digital termasuk aplikasiaplikasi digital yang berguna menunjang pembelajaran dalam rangka mencapai tujuan pembelajaran. Seorang guru pun harus memiliki kompetensi literasi digital. Komponen literasi digital meliputi (1) pengoperasian perangkat keras dan perangkat lunak, (2) literasi data dan informasi, (3) kolaborasi dan komunikasi, (4) kreasi konten digital, (5) keamanan, (6) problem solving, (7) kompetensi terkait pekerjaan (Law et al., 2018). Pada gambar 2 adalah kegiatan materi pertama.

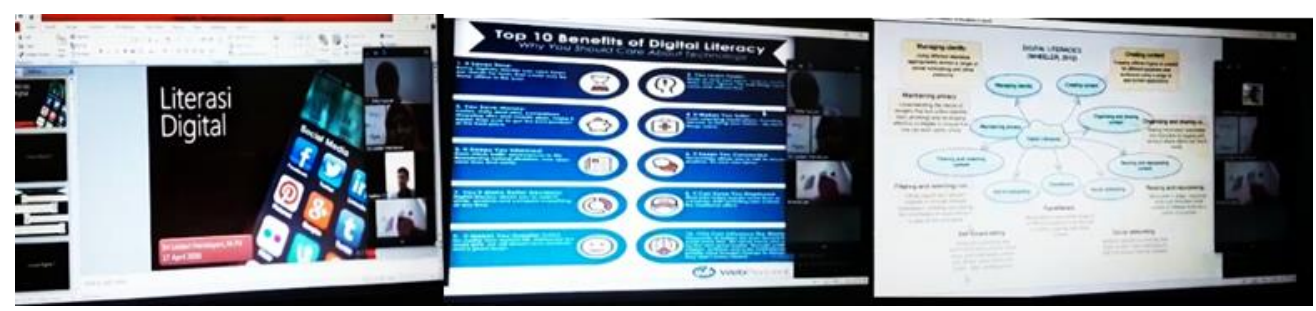

Gambar 2. Rangkaian Pemaparan Materi 1

Setelah sesi pertama selesai, selanjutnya dilakukan paparan materi terkait langkah-langkah pemanfaatan aplikasi Kahoot dalam pembelajaran khususnya pembuatan soal. Pada sesi 2 ini, setiap langkah pemanfaatan Kahoot dalam membuat soal diberikan agar peserta mengetahui terlebih dahulu langkah yang benar sebelum mempraktekkannya. Paparan materi dilakukan sekaligus demonstrasi secara langsung. Contoh pada langkah pertama, untuk memanfaatkan aplikasi Kahoot maka bisa dengan cara melalui website www.kahoot.com. Pemateri kemudian mempraktekkannya di browser cara membuka website Kahoot. Cara ini dilakukan untuk memudahkan peserta memahami pemanfaatan Kahoot dengan lebih cepat. Selain itu, peserta juga diminta untuk mensimulasikan secara langsung apa yang didemonstrasikan oleh pemateri. Pemateri kemudian mulai mempraktekkan cara membuat akun di aplikasi Kahoot secara gratis. Selanjutnya pemateri menjelaskan cara membuat tantangan atau cara membuat kuis, menuliskan soal, menuliskan pilihan jawaban, menentukan waktu pengerjaan untuk masing-masing butir soal yang dibuat, menuliskan judul tes yang dibuat, 
memilih cara memainkan Kahoot bagi siswanya, menentukan waktu pengerjaan tes, dan soal berbasis Kahoot siap digunakan. Selanjutnya pemateri mendemonstrasikan bagaimana cara menggunakan atau cara bermain Kahoot. Pemateri memposisikan diri seolah-olah sebagai siswa yang akan mengerjakan tes dengan aplikasi Kahoot buatan guru. Pada bagian ini juga peserta diminta ikut serta mencoba hasil tes yang telah dibuat. Cara ini diberikan agar guru dapat melihat bagaimana nanti siswanya akan mengerjakan soal yang dibuat jika menggunakan Kahoot sebagai salah satu aplikasi evaluasi pembelajaran. Pemateri kemudian memberikan simulasi cara memperoleh informasi hasil tes bagi guru dengan aplikasi Kahoot tersebut. Salah satu manfaat atau keuntungan menggunakan Kahoot adalah guru dipermudah dalam memperoleh skor nilai siswa dan menghemat waktu tanpa melakukan koreksi. Hal ini berbeda jika guru masih menggunakan tes tertulis. Selama proses kegiatan demonstrasi dan simulasi, peserta dapat bertanya langsung terkait hal yang kurang dipahami maupun kendala yang dihadapi dalam proses simulasi.

Gambar 3 adalah gambar rangkaian kegiatan materi 2 dan praktek simulasi.

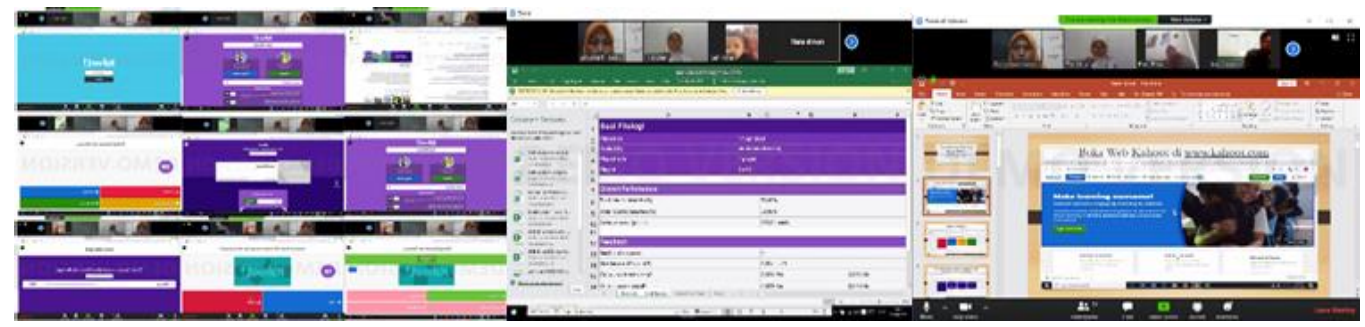

Gambar 3. Rangkaian Pemaparan Materi 2

Pemanfaatan aplikasi Kahoot dalam evaluasi pembelajaran khususnya membuat tes berbasis digital merupakan salah satu penerapan literasi digital bagi guru-guru di sekolah. Guru dapat menggunakan Kahoot sebagai salah satu variasi cara mengukur dan menilai kemampuan siswa dalam mencapai tujuan pembelajaran dengan cara lebih menarik dan menantang. Hal ini Kahoot diciptakan berbasis permainan dan tantangan. Siswa mengikuti tes atau kuis namun terasa seperti bermain. Kahoot terbukti memiliki banyak manfaat dalam pembelajaran diantaranya, dapat meningkatkan minta, motivasi, dan mempermudah evaluasi pembelajaran dan mempermudah menganalisis hasil tes (Alfansyur \& Mariyani, 2019; Centauri, 2019; Dannari \& Muna, 2019; Hartanti, 2019; Mustikawati, 2019; A. R. Putri \& Muzakki, 2019; V. V. E. Putri \& Asrori, 2019; Rofiyarti \& Sari, 2017; Wigati, 2019). Pelaksanaan kegiatan pengabdian masyarakat ini diakhiri dengan sesi berfoto bersama melalui aplikasi zoom meeting. Foto sesi bersama dapat dilihat pada gambar 4. 


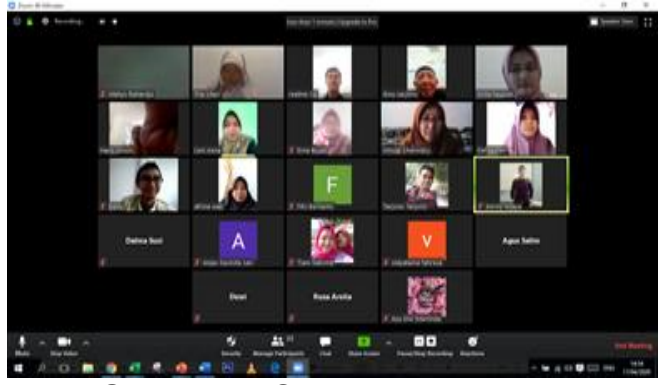

Gambar 4. Sesi Foto Bersama

\section{KESIMPULAN}

Kegiatan pengabdian masyarakat yang telah berhasil dilaksanakan ini dapat dirasakan secara langsung manfaatnya oleh peserta, karena peserta atau para guru dapat langsung mengimplikasikan hasil dari pelatihan pembuatan soal dalam kegiatan Pembelajaran Jarak Jauh (PJJ) yang saat ini diterapkan di sekolah akibat kondisi merebaknya wabah Covid-19. Pelatihan Pembuatan Soal Berbasis Digital dengan menggunakan aplikasi Kahoot telah menambah wawasan tentang pentingnya pemahaman atas literasi digital serta meningkatkan kemampuan para guru dalam membuat soal berbasis digital yang menyenangkan para siswa.

Saran untuk tindak lanjut kegiatan ini dapat dilakukan pelatihanpelatihan lainnya seperti pembuatan bahan ajar yang memanfaatkan teknologi untuk hasil yang lebih kreatif dan inovatif untuk meningkatkan kemampuan maupun profesionalisme guru dalam mengajar dan memanfaatkan perkembangan teknologi yang ada.

\section{UCAPAN TERIMA KASIH}

Terimakasih kepada Universitas Muhammadiyah Prof. Dr. Hamka yang telah memberikan dana untuk kegiatan ini melalui Lembaga Pengabdian dan Pemberdayaan Masyarakat (LPPM) Universitas Muhammadiyah Prof. Dr. Hamka, sehingga kegiatan ini dapat terlaksana dengan baik dan lancar tanpa ada halangan berarti.

\section{DAFTAR RUJUKAN}

Alfansyur, A., \& Mariyani. (2019). Pemanfaatan Media Berbasis Ict "Kahoot" Dalam Pembelajaran PPKN Untuk Meningkatkan Motivasi. Bhineka Tunggal Ika: Kajian Dan Ptaktik PKn, 6(2), 208-216. https://doi.org/10.36706/jbti.v6i2.10118

Belshaw, D. (2011). What is digital literacy? A Pragmatic investigation. In University of dURHAM.

Centauri, B. (2019). Efektivitas Kahoot! Sebagai Media Pembelajaran Kuis Interaktif Di Sdn-7 Bukit Tunggal. Prosiding Seminar Nasional Pendidikan Mipa Dan Teknologi (SNMPT II) 2019, 124-133.

Dannari, G. L., \& Muna, U. L. (2019). Pemanfaatan Media Pembelajaran 
Majalah dan Kahoot dalam Kegiatan Pembelajaran Sejarah di SMAN 1 Paggul Kelas XI IPAS 1. Jurnal Pendidikan Sejarah Indonesia, 2(2), 153-163. https://doi.org/10.17977/um033v2i22019p153

Darmaningrat, E. W. T., Ali, A. H. N., Wibowo, R. P., \& Astuti, H. M. (2018). Pemanfaatan Aplikasi Digital Learning Untuk Pembelajaran Pengayaan Di Sekolah Menengah Kota Surabaya. Seminar Nasional Sistem Informasi Indonesia, November, 85-95.

Hartanti, D. (2019). Meningkatkan Motivasi Belajar Siswa Dengan Media Pembelajaran Interaktif Game Kahoot Berbasis Hypermedia. Prosiding Seminar Nasional PEP 2019, 78-85.

Law, N., Woo, D., de la Torre, J., \& Wong, G. (2018). A Global Framework of Reference on Digital Literacy for Indicator 4.42. In unesco Institute for Statistics.

Mustikawati, F. E. (2019). Fungsi Aplikasi Kahoot sebagai Media Pembelajaran Bahasa Indonesia. Seminar Nasional P Bulan Bahasa (Semiba) 2019, O(0), 99-104.

Purnanto, A. W., \& Mahardika, A. (2016). Pelatihan Pembuatan Soal Interaktif Dengan Program Wondershare Quiz Creator Bagi Guru Sekolah Dasar Di Kota Magelang. WARTA LPM, 19(2), 141-148. https://doi.org/10.23917/warta.v19i2.2748

Putri, A. R., \& Muzakki, M. A. (2019). Implemetasi Kahoot sebagai Media Pembelajaran Berbasis Digital Game Based Learning dalam Mengahadapi Era Revolusi Industri 4.0. Prosiding Seminar Nasional Universitas Muria Kudus, 217-223.

Putri, V. V. E., \& Asrori, M. A. R. (2019). Pemanfaatan Digital Game Base Learning Dengan Media Aplikasi Kahoot.It Untuk Peningkatan Interaksi Pembelajaran. INSPIRASI: Jurnal IImu-IImu Sosial, 16(2), 141-150. https://doi.org/10.29100/insp.v16i2.1430

Rofiyarti, F., \& Sari, A. Y. (2017). TIK untuk AUD: Penggunaan Platform "Kahoot!" dalam Menumbuhkan Jiwa Kompetitif dan Kolaboratif Anak. PEDAGOGI: Jurnal Anak Usia Dini Dan Pendidikan Anak Usia Dini, 3(3b), 164-172. https://doi.org/10.30651/pedagogi.v3i3b.1066

Wigati, S. (2019). Penggunaan Media Game Kahoot Untuk Meningkatkan Hasil Dan Minat Belajar Matematika. AKSIOMA: Jurnal Program Studi Pendidikan Matematika, 8(3), 457-464. https://doi.org/10.24127/ajpm.v8i3.2445 